\title{
Study of the Pollution Generated by Engine Oils Applied on Building Woods to Control Termites
}

\author{
*Timothée NSONGO ${ }^{1,2,3}$, Hilaire ELENGA ${ }^{2,3}$, Bernard MABIALA $^{5}$, David BILEMBI ${ }^{4}$, \\ Ferland NGORO ELENGA ${ }^{1,3}$ \\ ${ }^{1}$ Groupe de Recherches sur les Propriétés Physico - Chimiques et Minérales des Matériaux Université \\ Marien NGOUABI, Brazzaville, CONGO \\ ${ }^{2}$ Centre de Recherches Géologiques et Minières, Brazzaville, CONGO \\ ${ }^{3}$ Faculté des Sciences et Techniques, Université Marien NGOUABI, B.P. 69 Brazzaville, CONGO. \\ ${ }^{4}$ Ecole Nationale Supérieure Polytechnique, Université Marien NGOUABI, Brazzaville, CONGO \\ ${ }^{5}$ Laboratoire Mécanique, Energétique et Ingénierie, Ecole Nationale Supérieure Polytechnique, \\ Université Marien NGOUABI, Brazzaville, CONGO
}

\begin{abstract}
Summary: The application of engine oils or diesel fuel on the building woods is one of the most commonly used means to control termite invasion in the Congo. Even if this method appears efficient in protecting the wood, it generates a great indoor pollution which has a health impact. Gas chromatography coupled to mass spectroscopy was used in this study to assess the composition of used engine oils and new engine oils. The oils and diesel fuel over time evolution on wood substrate was studied to prevent pollution.
\end{abstract}

The results achieved showed a predominance of hydrocarbon structures which are very toxic to human health, most of which are considered as carcinogenic and even responsible for many respiratory and pulmonary diseases.

The study showed that the effect of the pollution depended on how long one stayed indoors and on the nature of the wood. The study also showed that it was better to use diesel fuel in the fight against termites on the wood and that the coatings on the kambala took eleven days and ten on the limba.

Keywords: Used engine oil; new engine oil; wood, Kambala, limba, chromography

\section{INTRODUCTION}

Problems related to the air pollution have become a permanent concern for public authorities, scientists and even the civil society.

The use of wood in the construction industry plays a major role in the control of the atmospheric carbon cycle and in the limitation of greenhouse gas emission. The researches conducted by G. MABIALA [2] and quite recently by K.BONGO [1] on a comparative study of the physical and mechanical properties of the finished wood of the Congo natural forests have shown that wood species such as the limba and the kambala have remarkable physical and mechanical properties to be used in the construction of habitat frameworks. But because of its very nature, the wood remains sensitive to environmental factors, biological agents of degradation and particularly to termites.

To protect the wood against termite attacks a well-known practice in the Congo is to apply used engine-oils and diesel fuel on the construction wood. Even if this technique is efficient in protecting the wood, it generates an important pollution. Being hydrocarbon produtcs, these coatings cause important pollution nuisances inside the habitats due to the effects of their interaction with the construction wood through gas releases and very toxic microparticles at the origins of many pathologies such as : lung cancers, respiratory diseases [14],[15]. These gases and microparticles produced can cause pollution problems of the indoor air [15], [16], [17],[18 ],[19].

So as to prevent any pollution problem due to the coatings applied on the construction wood to control termites, [8],[9],[13],[14]. This survey aims at preventing the health effects and toxicity generated by the pollution of used engine oils and diesel fuel in comparison with the new oil with respect to exposure time $[3,4,5,6,7]$. 


\section{MeThODOLOGY}

\subsection{Choice of the Coatings used in the Congo}

Among the most commonly used coatings to protect the wood against termites figure: the diesel fuel, the new and the used engine oils. We applied these coatings respectively on the kamabala (write kambala not kamabala) and the limba to assess their absorption and desorption mechanisms.

\subsection{Operating Mod}

In order to find out the composition of these coatings (diesel fuel, new and used engine oils), the chemical analysis of the samples was conducted by gas chromatography.

That chromatography is a method used to conduct a qualitative and quantitative analysis of gases and volatile liquids. It can be applied for small quantities and for components of complex blendings. The sample (vapour or gaz) is selectively adsorbed in a stationary phase and it is carried over at constant flow in a mobile phase. The separation of the different components is due to the differences of the various constituents in affinity for the stationary phase.

It is a barely volatile liquid with adsorbent properties (the boiling temperature far superior to the temperature of the experimental set-up). The liquid is impregnated in small amount on a solid porous backing (a continuous and uniform bed of granules). This stationary phase in the column.

In the present study, the hydrogen, obtained from bottles whose flow could be controlled was used as a non-reactive gas. It was designed to cause a uniform drift of the fumes of the samples.

A chromatograph made of three essential organs: the jet chamber, the detectorand the column.

The sample is inserted by means of a serynge by drilling an elastomer pastille. The injection must be fast so as to obtain uniform results. The volume injected was in the order of a few $\mu 1$ for the liquids and a few $\mathrm{ml}$ for the gases. The temperature was regulated so as to maintain all the components of the samples in a gaseous state. The carrier gas was also in the temperature-controlled room. The choice of the carrier gas depends on the product to be analyzed. It also has an impact on the efficiency of the separation of the different compound elements.

It was placed in a temperature-controlled oven. It was made of a stainless steel pipe. The inside diameter was about 2 to $6 \mathrm{~mm}$ and it varied between 1 to $10 \mathrm{~m}$ long. It was rolled up to reduce bulk. It was full of the stationay phase.

These are differential detectors senstive to the concentration variations of the constituents coupled to a recording device. A detector indicates a Gauss curve like trail forming peaks. Every peak indicates the passing of one of the analyzed sample compounds through the detector.

\section{RESUlTS AND DISCUSSION}

\subsection{Study of the New And used Engine Oils Composition}

The chromatographic spectrums of the new and used engine oils are presented respectively on figures ( $5 \& 6)$. The results achieved both for new and used engine oils show sharp peaks. The results of the reference [13] helped us identify the different peaks.

The chemical analysis of the peaks observed, respectively, for the chromatographic spectrums of the new and used engine oils revealed the presence of chemical organic compounds distinctive of hydrocarbon structures. These results showed a predominance of the eicosane and benzene compounds. These chemical compounds are very toxic to human health, most of them are said to be carcinogenic and even causing several respiratory, life-threatening diseases [26]

Even if it looks like the spectrum of the new engine oil, the engine used oil spectrum shows new peaks (fig.6) between 15 and 30 minutes. These peaks reveal the presence of new organic compounds which can be explained by the deterioration of the oil used as engine lubricant

These results are therefore in line with those obtained by F.O. Cotton et al [13] 


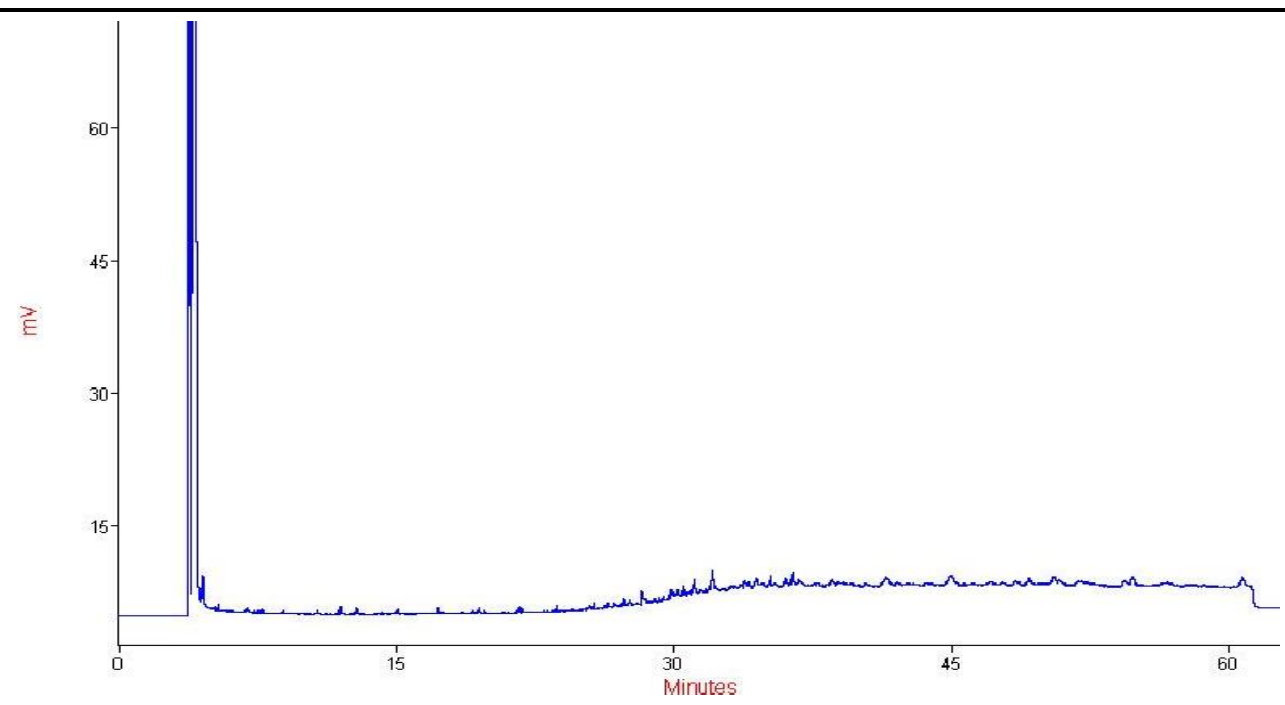

Figure5. Chromatogram of the new engine oil

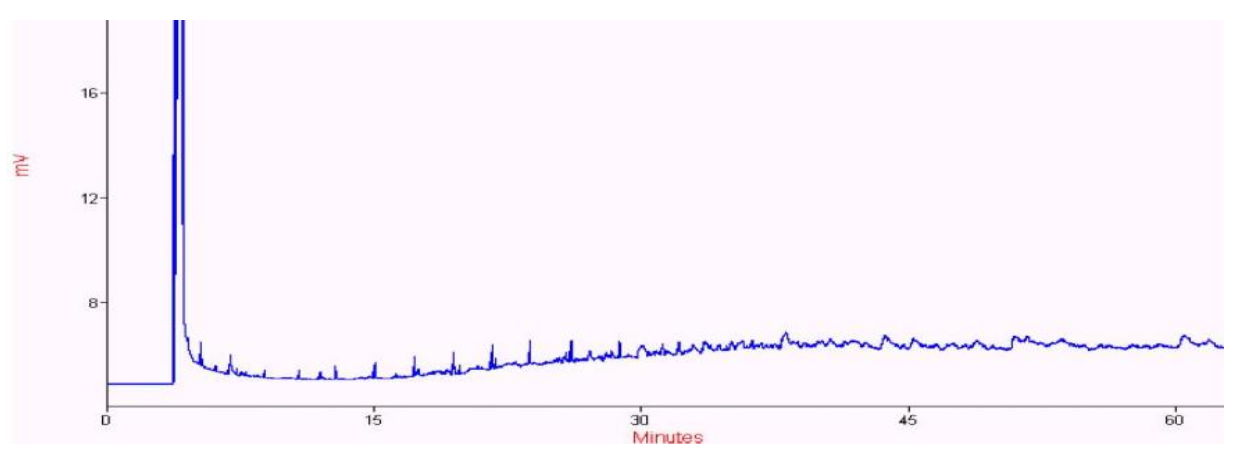

Figure6. Chromatogramof the used engine oil

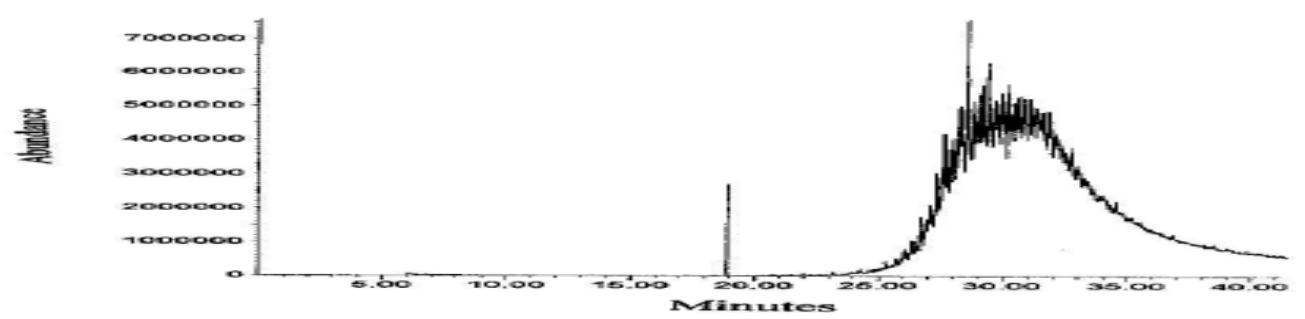

Figure7. Magnification of the new engine oil chromatographic spectrum Ref [13]

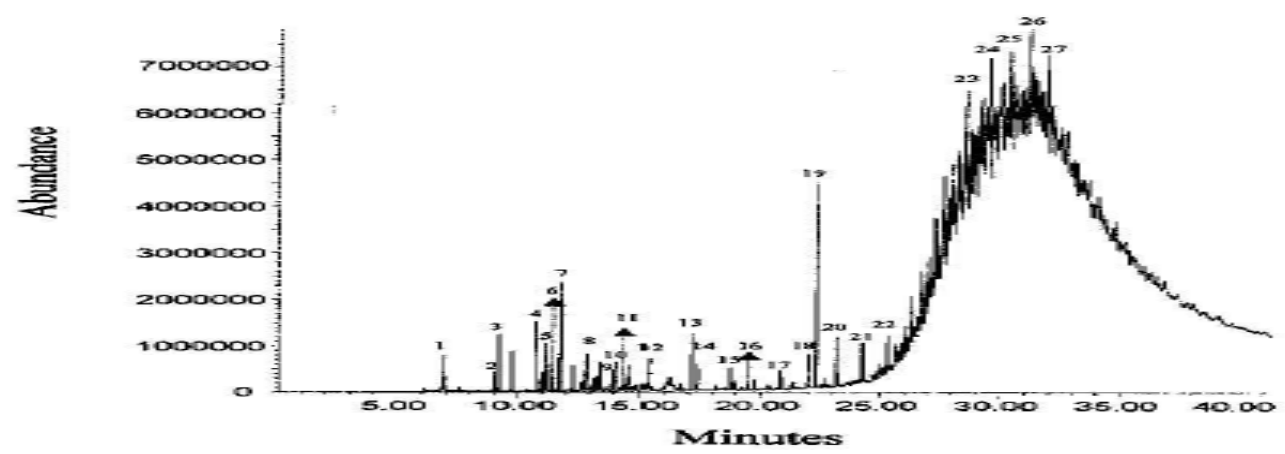

Figure8. Magnification of the used engine oil chromatographic spectrum Ref [13]

Table1. Chemical compounds present in the new and used engine oils Ref [13]

\begin{tabular}{|l|l|}
\hline organic componentspresent in the new and used engine oils & Output time of organic compounds (minutes) \\
\hline (1). Toluène & 18 \\
\hline (19) Méthyl undecanoate & 23 \\
\hline (19) methyltridecanoate & 23 \\
\hline (23), (25), (26) et (27) Eicosane & 25 à 42 \\
\hline (24)1-bromopentadecane & 27 \\
\hline
\end{tabular}


Timothée NSONGO et al.

Table2. Chemical compounds found in the used engine oil due to the deterioration of the engine oil Ref [13]

\begin{tabular}{|l|l|}
\hline organic components present in the new and used engine oils & Output time of organic compounds (minutes) \\
\hline (2) 1,2-dimethyl benzène & 10 \\
\hline (3) p-xylène & 10 \\
\hline (4) Naphtalene & 11 \\
\hline $\begin{array}{l}\text { (5) 1,2,3-trimetyl benzene; (6) 1-éthyl-2-methyl benzene } \\
;(7) 1,2,3 \text {-trimethylbenzene ;(8)1-éthyl-3,5-dimethyl } \\
\text { benzene; (9) 1,2,3,5 tetramethylbenzene; (10) 1-methyl 1-3- } \\
\begin{array}{l}\text { (1 methylethyl) benzene;(11) 1-methyl -2-(2propenyl)- } \\
\text { benzene }\end{array}\end{array}$ \\
\hline $\begin{array}{l}\text { (12) naphthalene; (13) 1-methyl-naphtalene; (14) 2-methyl- } \\
\text { naphthalene; 1-methyl-naphthalene }\end{array}$ & 12 à 15 \\
\hline 5-methyl undecane & 15 à 17 \\
\hline (17) hexadecane; tricosane; heneicosane;(18) eicosane & 18 à 19 \\
\hline
\end{tabular}

\section{STUDY OF THE DESORPTION OF THE DIESEL FUEL, NEW AND USED ENGINE OILS ON THE KAMBALA AND THE LIMBA}

The diesel fuel, new and used engine oils were applied, respectively on the kambala and limba woods in order to understand the evolution of the drying mechanism. The oils and diesel fuel loss in mass based on time was conducted by means of weighings to study the impact of the coating (oil) used on the desorption mechanism

\subsection{Impact of the Coatings on the Kambala Absorption}

The results achieved, as presented in figure 9 show that the level of each coating, oil or diesel fuel, decreases based on the exposure time. We notice that whatever the coating (diesel fuel, oil) applied on the kambala wood may be the level of the product applied as a coating decreases. These results show that the diesel fuel is eliminated after 10 days whereas the engine oils used and new are completely adsorbed, respectively after 11 and 12 days.

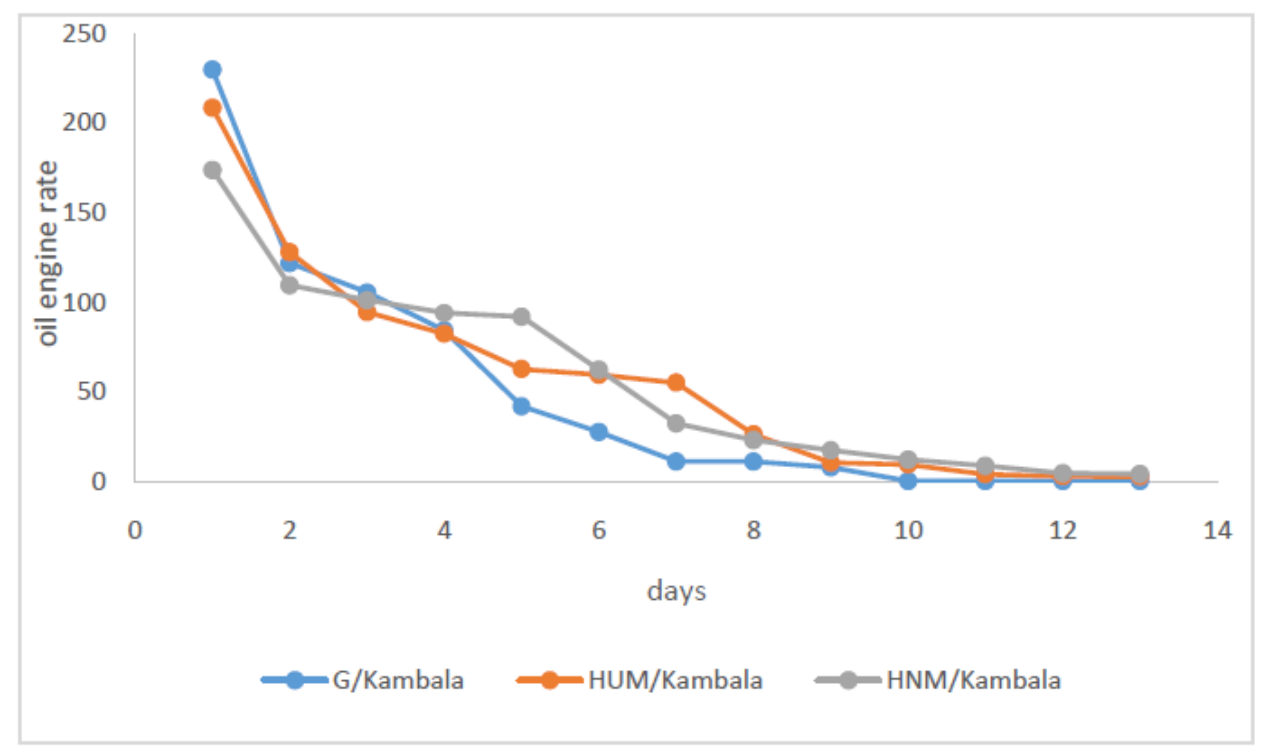

Figure9. Variations of the product level in relation to time

HUM: used engine oil, HNM: New engine oil, G: diesel fuel

\subsection{Influence of Wood Species on the used Engine Oil Drying Time}

In order to understand and compare the drying mechanism we applied used engine oil on the kambla and the limba. The results in figure 11 show that the quantity of used engine oil on the limba decreases in a linear fashion and wears off after the first eleven days of its application. On the contrary the quantity of the used engine oil decreases per step when applied on the kambala and lowers strongly from the seventh day and nullifies afterwards.

These results show that the adsorption process of the used engine oil is completed more quickly on the kamabla than on the limba. 


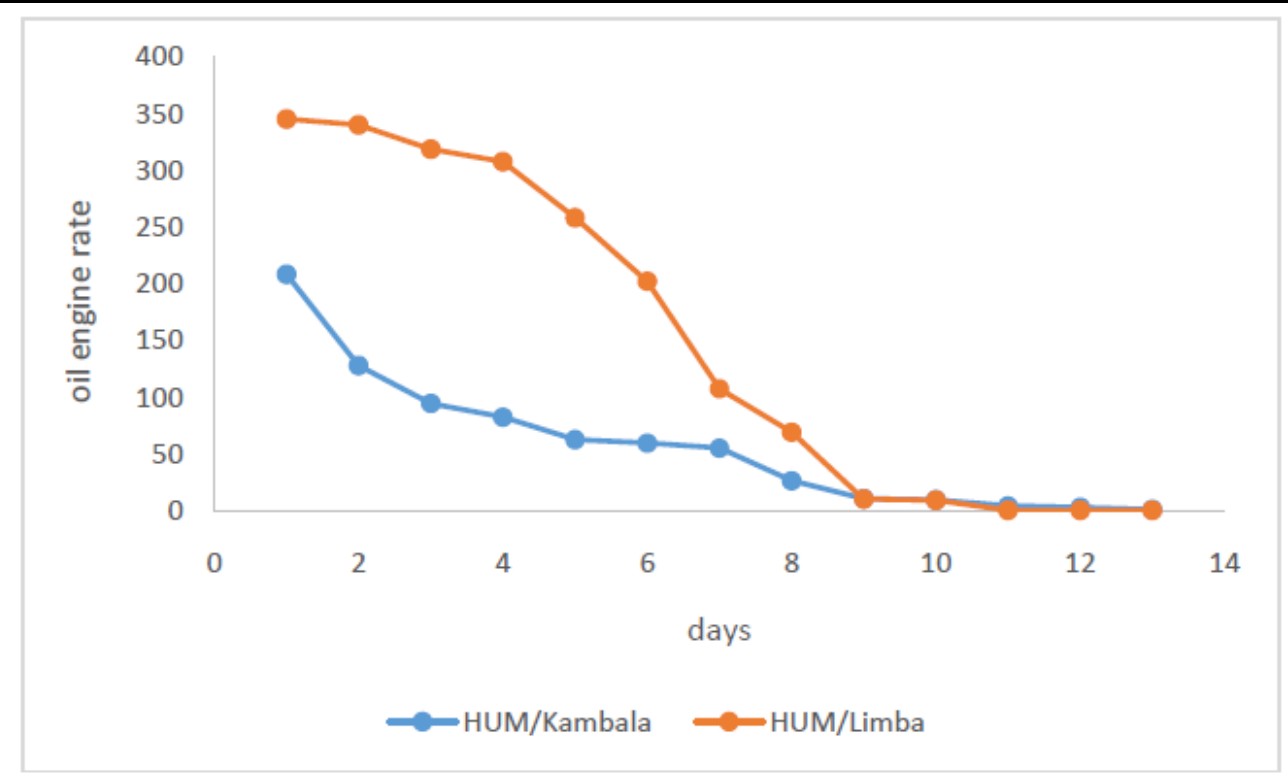

Figure10. Variations of the used engine oil level in relation to time

\subsection{Influence of Wood Species on the New Engine Oil Drying}

We applied new engine oil respectively on the limba and the kambala in order to compare their drying mechanisms (figure 12). The level of the new engine oil declines exponentially based on time. The level of the new engine oil applied on the kambala declines more slowly after the first nine days of its application then nullifies after ten days which explains why the new engine oil settles down on the wood. Conversely, for the limba, the quantity of the new engine oils decreases fast and nullifies after ten days.

These results show that the kambala could be less permeable to the oil movements of the new engine oil than the limba.

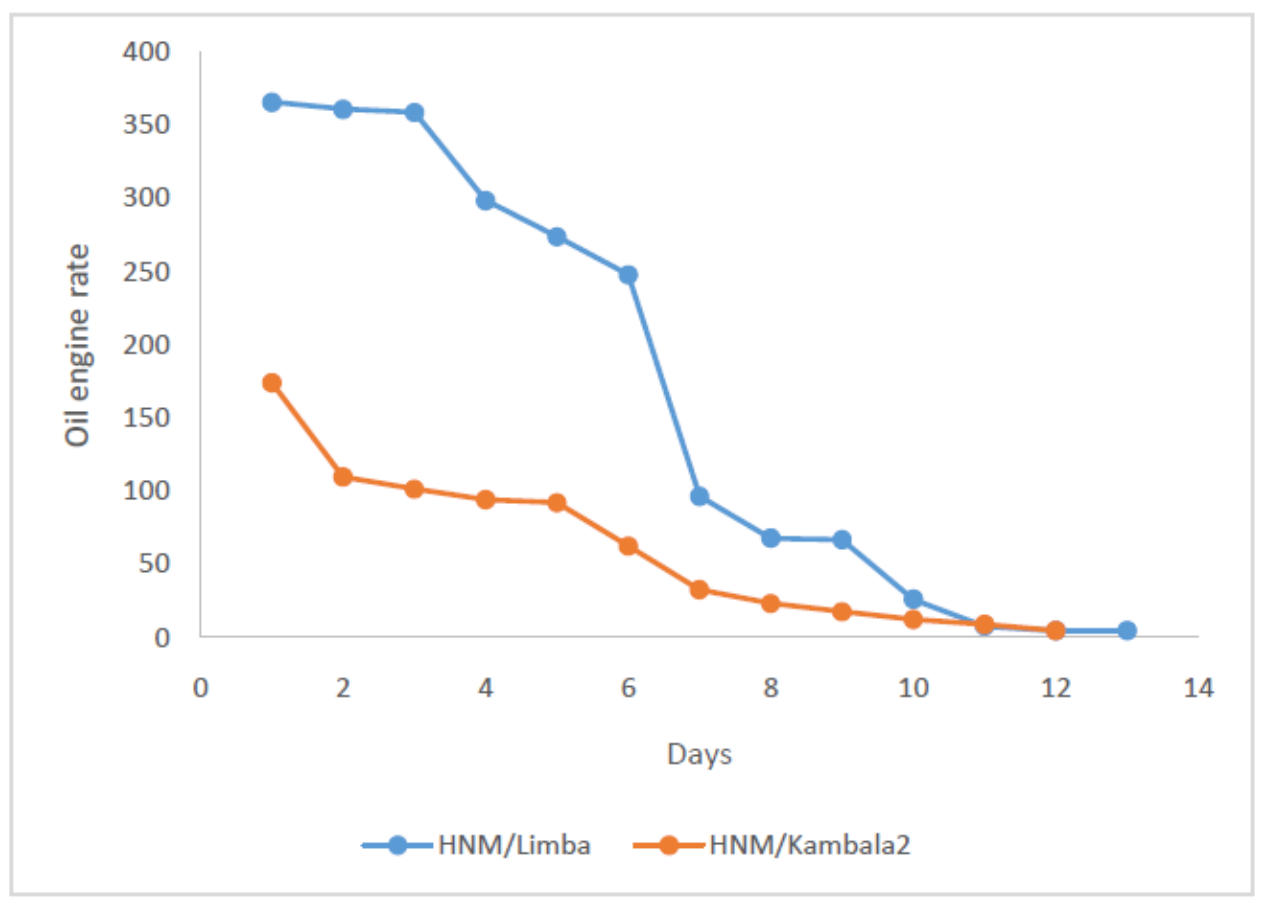

Figure11. Variations of the new engine oil rate on the limba and kambala in relation to time

\subsection{Influence of Wood Species on the Diesel Fuel Desorption}

Figure 13 shows the drying kinetics of the diesel fuel on the limba and the kambala. The quantity of the diesel fuel applied on the limba declines in a linear manner and shows a break on the sixth day. The decline of the diesel fuel quantity applied on the limba is completed gradually. After six days we notice that the diesel fuel drying mechanism on the limba or the kambala is the same. 


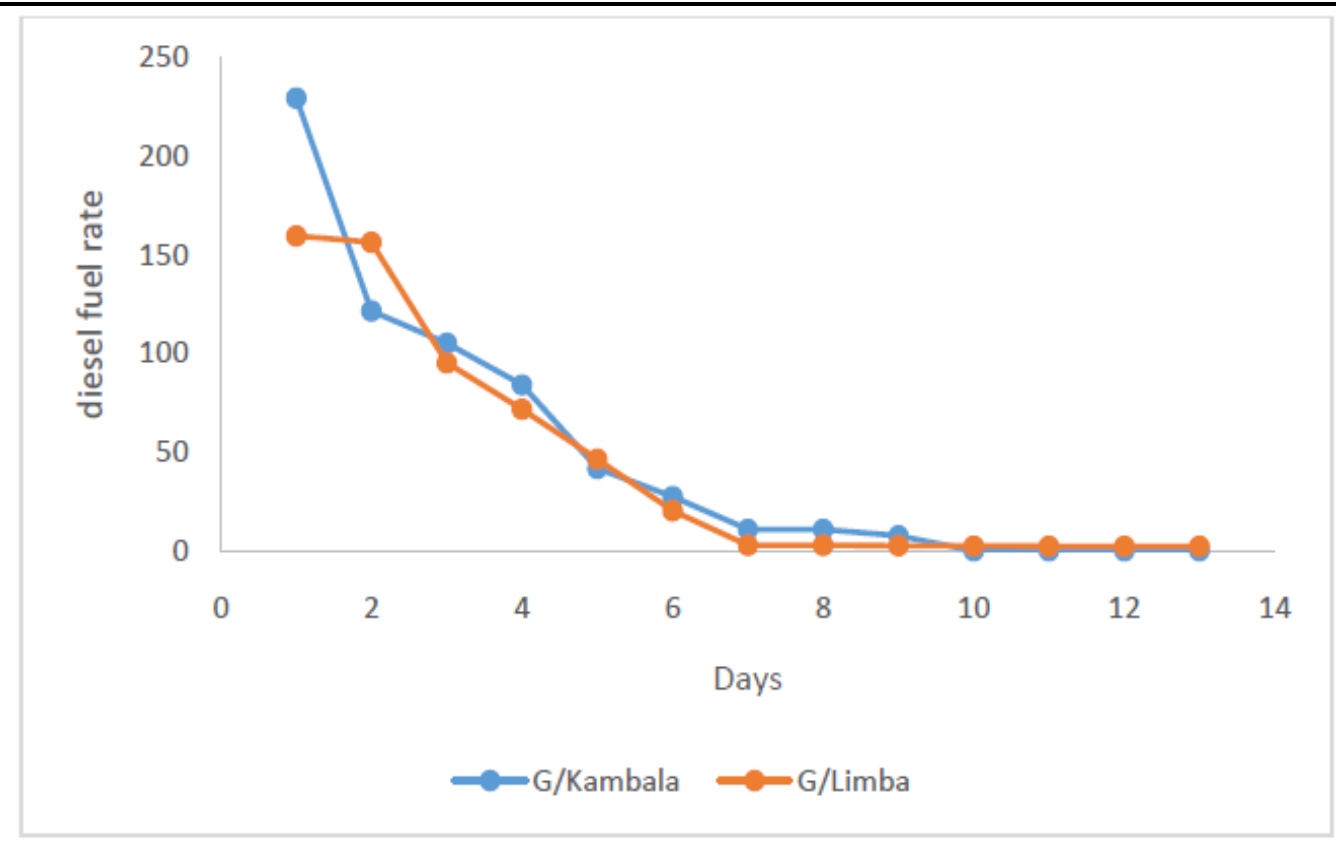

Figure13. Variations of the diesel fuel quantity in terms of percent in relation to time

Indeed, the results achieved show that when the diesel fuel, the new and used engine oils are applied on the wood, a desorption period of at least 10 days is needed for the new or used engine oils or the diesel fuel on the kambala. Nevertheless, a period of at least 11 days is necessary after the application of the new or used engine oils on the limba. This period is shorter in the case of the diesel fuel on the limba.

Whatever the wood species, the desorption mechanism is fairly short for the diesel fuel compared with the new and used engine oils.

It is better to use the diesel fuel to fight termites and avoid staying indoors for at least 10 days.

\section{Conclusion}

The present survey has enabled us to identify the toxic elements present in the new and used engine oils by means of chromatographic analysis. These results show out a predominance a hydrocarbon structures identified after 40 minutes. The desorption study shows that it is better to use the diesel fuel in the fight termites on the wood. The drying mechanism of the diesel fuel is the same on the limba and the kambala whereas the new or used engine oils drying mechanisms depend on the nature of the wood.

The results has shown that the minimum time to prevent engines oil effect is about 10 days.

\section{REFERENCES}

[1] K. BONGO, A comparative study of the Physical and Mechanical Properties of the Finished woods of the Congo Natural Forests Exposed to Rainfall, C.A.P.E.S. Dissertation, Ecole Normale Supérieure, 2012.

[2] G. MABIALA, Effect of the immersion of the floated Congo Natural Forest timbers on the water environment and on the variation of the mechanical properties during the drying up time,DEA Dissertation, Faculté des Sciences et Techniques, 2012.

[3] S. Charmon et B. jouez, Survey of the physical and mechanical properties of the Europe and Japan larch woods and their hybrid, Doctoral thesis, Faculty of Agricultural Sciences, 2003

[4] M. Olivier PIGNOLET, Optimisation of the softwood lumber (Use class 4) by means of alkenyl succinic anhydride of plant origin, Doctoral Thesis in Agro-Ressources Sciences, Toulouse University, November, 2008

[5] Raysal M., Wood Preservation: Standards guide. CTBA, Paris, 2004.

[6] Shelton G.T., Grace J.K., Termite physiology in relation to wood degradation and termite control. In: Wood Deterioration and Preservation - Advances in Our Changing World. ACS Symposium Series845pp 242-252, 2003. 
[7] Thibaud SURINI, Dynamic analysis of the wood, wood based composites and plant fibre biodegradation Doctoral Thesis in Wood Sciences, University of Bordeaux 1,Doctoral School of Sciences and the Engineer, October 2009

[8] P.Stéphane, The wood in The Building Industry, Regulation: Insects with Wood Boring Larvae and Termites. Doctoral Thesis

[9] Z. Harijona, Thermal Impact of wood claddings on the interior atmosphere of the houses, application of the Traditional Habitat in France and in Madagascar. Doctoral Thesis, National Institute of Applied Sciences, Gembleux, 2011

[10] Protection of New Buildings Against Termites and other Xylophagous Insects, France, September 2010

[11] J.B. Masson, the Chemical quality of the Indoor Air in French Houses. Doctoral Thesis, University of Technology, Compiègne, September, 2010

[12] H. DEBEAUX, The Pollution of indoor spaces air, Doctoral Thesis,(Ph.D) Joseph Fourier University, Grenoble 2010

[13] F.O. Cotton, M.L. Whisman, S.W. Gowtzinger\& J.W. Renolds, Analysis of used motor oils. Hydrocarbon processing 131-140, Procedings of the Indiana Academy of Science 112(2): 109116, 2003. 